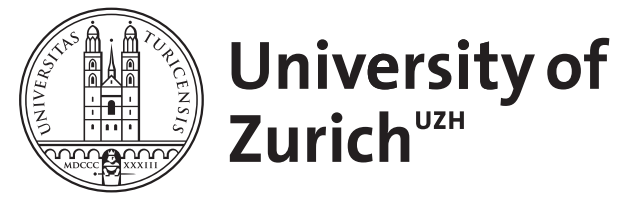

\title{
Die Kunst der Übertreibung : Hyperbolik und Ironie in spätmittelalterlichen Minnereden
}

\author{
Köbele, Susanne
}

Posted at the Zurich Open Repository and Archive, University of Zurich

ZORA URL: https://doi.org/10.5167/uzh-93259

Book Section

Published Version

Originally published at:

Köbele, Susanne (2006). Die Kunst der Übertreibung : Hyperbolik und Ironie in spätmittelalterlichen Minnereden. In: Lieb, Ludger; Neudeck, Otto. Triviale Minne? : Konventionalität und Trivialisierung in spätmittelalterlichen Minnereden. Berlin: De Gruyter, 19-44. 


\section{Die Kunst der Übertreibung Hyperbolik und Ironie in spätmittelalterlichen Minnereden}

"Einen Engel! Pfuy! das sagt jeder von der seinigen!
Nicht wahr? Und doch ..."
(Goethe)
"Aber was bedeutet ein Gleichnis?
Ein wenig Wirkliches mit sehr viel Übertreibung."
(Musil)

I. veritatis transgressio

Übertreibungen sind riskant. Sie setzen die Wahrheit aufs Spiel (Übertreibungen ,lügen), den Ernst (Übertreibungen, spielen) und den Kunstcharakter (Übertreibungen wirken ,künstlich). Das steht alles schon bei Quintilian, der die Ambivalenz hyperbolischer Rede mit einem Maßhaltegebot auffängt: Auch wenn jede Hyperbel notwendig das Glaubliche überschreite (ultra fidem), dürfe sie gleichwohl über ein bestimmtes $\mathrm{Maß}$ nicht hinausgehen (non tamen esse debet ultra modum), werde doch auf keine andere Weise schneller Künstelei bewirkt. ${ }^{1}$ Wer die Grenze des Angemessenen mißachte, provoziere allenfalls Gelächter, kein urbanes (risus urbanitatis), sondern ein vulgäres und törichtes (risus stultitiae). Kurz, Übertreibung darf nicht übertrieben werden. So bündig wie normativ definiert

1 M. F. Quintilianus: Institutionis Oratoriae Libri XII. Ausbildung des Redners. Hg. von Helmut Rahn. 2 Bde. Darmstadt ${ }^{3} 1995,8,6,73$, S. $248 f$.: [...] servetur mensura quaedam. quamvis enim est omnis byperbole ultra fidem, non tamen esse debet ultra modum nec alia via magis in cacozelian itur. 
Quintilian die Hyperbel in diesem Sinn als ,schickliches Hinausgehen über das Wahre" (Hyperbole: est haec decens veri superiectio). ${ }^{2}$

Die Auffassung der Hyperbel als Abweichung vom Maß bleibt bestimmend für die Rhetoriklehren des Mittelalters wie der Frühen Neuzeit, und sie bleibt zwiespältig. Unter der Voraussetzung, daß die Abweichung vom $\mathrm{Ma} \beta$ eine Abweichung von der Wahrheit einschließt (veritatis exces$\left.s i 0^{3}\right)$, muß sie es durchweg bleiben. Galfrid von Vinsauf, in seiner vom frühen 13. Jahrhundert an bis ins 15. Jahrhundert weit verbreiteten ,Poetria nova', räumt der Hyperbel (superlatio) immerhin acht Verse ein. Im Abschnitt über die Tropen des Ornatus difficilis gibt er ihr einen Platz zwischen Metonymie und Synekdoche (v. 1013-1021) ${ }^{4}$ und bewertet sie wie folgt: Hyperbolische Rede - sprachliches Übermaß (excessus) - verdiene dann Lob, wenn sie vernünftig dimensioniert sei. Fehle ihr hingegen das angemessene $\mathrm{Maß}$, beleidige sie Geist und Ohr. ${ }^{5}$ Kürzer faßt sich Eberhard der Deutsche in seinem ,Laborinthus', einer Galfrid-nahen Dichtungslehre aus der ersten Hälfte des 13. Jahrhunderts, die im deutschen Spätmittelalter eines der ,wichtigsten und verbreitetsten Schulbücher" werden sollte. ${ }^{6}$ Wieder ist hier die Hyperbel erläutert als im Einzelfall angebrachte „Tendenz über das Maß hinaus“: „Mir kommt zu, den Gang der Rede weit über das Maß hinauszuführen, weiter als die strenge Regel des Wahren (veri regula recta) es fordert." ${ }^{\text {"7 }}$,Wahrheit' meint in den zitierten Fällen die Verbindlichkeit des vorgegebenen Sachverhalts (res) oder Stoffes (materia). Kontextabhängig kann der Wahrheitsbegriff sich verschieben. So definiert Nicolaus Dybinus, der sowohl die ,Poetria nova wie auch den ,Laborinthus' im 14. Jahrhundert ausführlich kommentiert,

2 Quintilian (Anm. 1), 8,6,67.

3 Superlatio est in dicendo veritatis excessio. Diese Hyperbel-Definition gibt im 12. Jahrhundert Thierry von Chartres in seinem Kommentar zur, Rhetorica ad Herennium': The Latin Rhetorical Commentaries by Thierry of Chartres. Hg. von Karin Margareta Fredborg. Leiden 1988 (Studies and texts 84), S. 217-361: ,Commentarius super Rhetoricam ad Herennium', hier 344,86 .

4 Vgl. Edmond Faral (Hg.): Les arts poétiques du XII ${ }^{e}$ et du XIII ${ }^{e}$ siècle. Recherches et documents sur la technique littéraire du moyen âge. Paris 1924. Nachdruck 1962, S. 194 262.

5 V. 1013-1021: Currat yperbolicus, sed non discurrat inepte | Sermo: refrenet eum ratio placeatque modestus | Finis, ut excessum nec mens nec abborreat auris. [Ich überspringe einige Beispielverse, die in v. 1020f. schließlich wie folgt kommentiert werden:] Mirifice laudes minuit modus iste vel auget: | Et placet excessus, quem laudat et auris et usus (Faral [Anm. 4], S. 228f.).

6 Franz Josef Worstbrock: Eberhard der Deutsche. In: 'VL 2 (1980), Sp. 273-276, hier Sp. 275; Text nach Faral (Anm. 4), S. 337-377. Vgl. Hans Szklenar: Magister Nicolaus de Dybin. Vorstudien zu einer Edition seiner Schriften. Ein Beitrag zur Geschichte der literarischen Rhetorik im späteren Mittelalter. München - Zürich 1981 (MTU 65), S. 85-99 (zu Dybinus' Kommentar des ,Laborinthus?).

7 Faral (Anm. 4), S. 337-377, v. 415f: Cursum sermonis mibi tendere convenit ult ra |Q u a m poscit veri regula recta pati. 
im geistlichen Kontext seiner ,Declaracio oracionis de beata Dorothea ${ }^{6}$ die Hyperbel (superlacio) zunächst allgemein als einen die Wahrheit überschreitenden Übertragungsvorgang: [...] diccio transsumitur ad significandum vltra veritatem rei. ${ }^{9}$ In einem zweiten Schritt unterteilt er dann den hyperbolischen modus transsumpcionis $(226,10)$ in einen Überbietungs-Vergleich (superlacio cum comparacione, Beispiel: „Er ist langsamer als eine Schnecke“, 226,22ff.) und in einen Modus, der außerhalb von Vergleichen angesiedelt sei (superlacio sine comparacione, 226,27ff.). Die Beispiele für diesen zweiten Modus, einen paradoxen „Vergleich ohne Vergleich“ (comparacio sine comparacione), sind nicht zufällig aus dem religiösen Bereich hymnischer augmentacio laudis genommen. Paradox sind sie insofern, als sie, wie Dybinus es formuliert, in keinem Punkt des Vergleichs Vergleichbarkeit gewährleisten (in nullo gradu qualitatis uel accidentis). Wenn beide Übertreibungstypen, der Vergleich und der „Vergleich ohne Vergleich“, bei Dybinus als excessus veritatis gelten $(226,18)$, als transgressio veritatis $(226,36)$, ist das ein Zeichen für eine Erweiterung des Wahrheitsbegriffs. Iulius Caesar Scaliger, Mitte des 16. Jahrhunderts, zählt die Hyperbel ganz lapidar wieder zu denjenigen Figuren, „die mehr aussagen, als in der Sache enthalten ist": [Hyperbole:] genus figurarum, quae plus dicunt, quam in re sit,$^{10}$ und wie schon Quintilian, der die Hyperbel als „besonders kühnen“ Tropus qualifiziert $(8,6,67)$, nennt auch Scaliger sie, mit Bezug auf Aristoteles und Cicero, ein „Zuviel“, einen sprachlichen „Exzess“, der zum Überfluß neige (excessus ad exuberantiam), ja zur Überfüllung (redundantiam), aufgrund seiner riskanten Entfernung von „Mitte und Mittelmaß“.11

Halten wir vorerst fest: In der traditionsbildenden Tropustheorie der Rhetorik ist die Hyperbel - nicht ohne widersprüchliche Implikationen definiert als, Überschreitung des Wahren'. Als rhetorischer Idealfall von Hyperbel gilt das rational regulierte, maßvolle Übermaßs. In dieser Traditionslinie ,ersetzt ${ }^{t}$ die Hyperbel einen usuellen Ausdruck durch einen inhaltlich übertreibenden. Verbindet man diese historische Perspektive mit einer systematischen, wird man freilich auch solche Fälle einkalkulieren, bei denen die Übertreibung nicht in einer einfachen Substitution aufgeht;

8 Samuel P. Jaffe: Nicolaus Dybinus' Declaracio oracionis de beata Dorothea: Studies and documents in the history of late medieval rhetoric. Wiesbaden 1974 (Beiträge zur Literatur des 15. bis 18. Jahrhunderts 5), S. 226f. (vgl. auch S. 134-136).

9 Ebd., S. 226,19f.

10 Iulius Caesar Scaliger: Poetices libri septem. Sieben Bücher über die Dichtkunst. Unter Mitwirkung von Manfred Fuhrmann hg. von Luc Deitz und Gregor Vogt-Spira. Bd. 2: Buch 3, Kap. 1-94. Hg., übersetzt, eingeleitet und erläutert von Luc Deitz. Stuttgart-Bad Cannstatt 1994, Kap. 73 (S. 502, Z. 8f.)

Ebd., Z. 13ff. 
wie auch ihr Nachbartropus, die Metapher, nicht im Ähnlichkeitskriterium (im simile), die Ironie nicht im Gegenteilkriterium (im contrarium). ${ }^{12}$

$\mathrm{Da}$ die rhetorische Substitutionstheorie das Phänomen sprachlicher Übertreibung unterbietet, darauf macht Quintilian selbst aufmerksam, weswegen ich noch einmal auf ihn zurückkomme. Im Kontext der oben zitierten Stelle $(8,6,75)$ führt er zugunsten der Hyperbolik ein Argument an, das man ein ,universalanthropologisches ${ }^{`}$ nennen könnte: Der Wunsch, Dinge vergrößern zu wollen (cupiditas res augendi), liege in der Natur des Menschen, denn niemand sei mit dem Gegebenen zufrieden. $\mathrm{Da} \beta$ dieses Argument moralisch heikel ist, demonstriert der Folgesatz: Solche „Gier" nach Überschreitung des Gegebenen sei uns freilich nachzusehen, weil wir damit keine festen Behauptungen aufstellten (quia non adfirmamus). ${ }^{13}$ Quintilian macht demnach folgendes Zugeständnis: Übertreibungen, dezente Übertreibungen, seien grundsätzlich willkommen, weil sie - sprachlich, imaginativ - Möglichkeiten vervielfältigen, über die reine „Affirmation“ des Gegebenen hinaus.

Quintilian zieht aber noch eine weitere Differenzierung ein. Geradezu geboten seien Übertreibungen dann, wenn der darzustellende Gegenstand selber schon jedes $\mathrm{Ma} \beta$ überschreitet (naturalem modum excessit). ${ }^{14}$ Das ist unmittelbar einleuchtend: Wenn der Gegenstand unabsehbar groß ist, bleiben der Maßstab (modus) und das Ausmaß (quantum) unbekannt. In diesem Fall sei es statthaft, übertreibend zu reden (amplius dicere), weil man besser zu weit gehe als hinter dem richtigen (Aus-)Maß zurückzubleiben. Das ist ein neuer Aspekt. Er besagt: Exzeptionelle Sachverhalte und Gegenstände verdienen, ja fordern sprachliche „Exzesse“, setzen sie doch alle Relationen, alle Maßhaltegebote außer Kraft. Abseits der antiken Situation forensischer Persuasionsrhetorik läßt sich für in diesem Sinn grenzüberschreitende Übertreibungen an die herois che Hyperbolik denken, die sich bindet an die spezifische „Exorbitanz des Helden“. 15

12 Vgl. im Überblick Wolfgang G. Müller: Ironie. In: RLW 2 (2000), S. 185-189, bes. S. $185 f$. Zur Ironie im Umfeld der Linguistik vgl. Wolf-Dieter Stempel: Ironie als Sprechhandlung. In: Das Komische. Hg. von Wolfgang Preisendanz und Rainer Warning. München 1976 (Poetik und Hermeneutik 7), S. 205-235.

13 Quintilian (Anm. 1), 8,6,75: [...] quia natura est omnibus augendi res vel minuendi cupiditas insita nec quisquam vero contentus est: sed ignoscitur, quia non adfirmamus (, [...] denn von Natur liegt in allen Menschen das Verlangen, die Dinge zu vergrößern oder zu verkleinern, und niemand gibt sich mit dem zufrieden, wie es wirklich ist. Jedoch finden wir Nachsicht dabei, weil wir ja keine festen Behauptungen aufstellen").

14 Ebd., 8,6,76: tum est byperbole virtus, cum res ipsa, de qua loguendum est, naturalem modum excessit („Eine Stiltugend ist die Hyperbel dann, wenn der Gegenstand selbst, über den man sprechen muß, das natürliche Ausmaß überschritten hat").

15 Dazu Klaus von See: Held und Kollektiv. In: ZfdA 122 (1993), S. 1-35; Hans Ulrich Gumbrecht: Funktionswandel und Rezeption. Studien zur Hyperbolik in literarischen Tex- 
Nahe liegt darüber hinaus die Hyperbolik des $\mathrm{H}$ y $\mathrm{m} n$ is $\mathrm{ch}$ e $\mathrm{n}$, deren Intensität aus der Vorstellung der Unüberbietbarkeit Gottes resultiert (hierher gehören Nicolaus Dybinus', Vergleiche ohne Vergleich). Nahe liegt drittens, weil auch sie nur immer wieder und nie vollständig gesagt werden kann, die Hyperbolik der L i e b e. Die Maßlosigkeit als Kunstmittel entspräche hier der Maßlosigkeit des Affekts. Für Wolframs von Eschenbach Willehalm, der alles drei zugleich ist - heroischer Held, heiliger Held und Minneheld - konnte Karl Bertau geradezu von einem „Zustand der Hyperbolik" sprechen, ${ }^{16}$ dessen Anstößigkeit Wolfram, Hyperbel an Hyperbel reihend, mit trockenem Witz verteidigt. Die zuletzt genannte Übertreibungskunst, die der Liebe, soll im Mittelpunkt der folgenden Überlegungen stehen.

\section{II. minne und mâze}

Sie, die Schönste, ich, der Leidendste: Diese Hyperbolik ist ein Grundmuster des höfischen Minnelieds seit seinen Anfängen. Heinrich von Morungen übertreibt die Negativsemantik der Liebe so: „Einen Baum hätte ich mit meiner Klage beugen können, ohne Werkzeug - sie schweigt" (MF 127,23); daß die Kritik, die auf die übertriebene Beständigkeit der Dame zielt, im selben Atemzug revoziert wird, gehört zum Spiel. Spätmittelalterliche Sänger, ihrerseits unter Überbietungszwang, um weder mit ihrer Liebe, noch mit ihrer Kunst unterhalb der Aufmerksamkeitsschwelle zu liegen, überbieten solche Hyperbolik noch einmal. So treibt der Tannhäuser die übertriebenen Forderungen der Dame mit einer Kette von Adynata ins Unmögliche (ich summiere aus den Liedern IX und X): „Ich soll ihr ein elfenbeinenes Schloß im Meer bauen, den Gral bringen, den Apfel des Paris, den Schutzmantel der Maria und die Arche Noah, soll ihr die Sterne vom Himmel, den Salamander aus dem Feuer holen und 1000 Lanzen verstechen wie Gahmuret - dann wäre ich ihr lieb." ${ }_{17}$ Der andere Pol solch skeptischer Unmöglichkeitsübertreibungen heißt dagegen: ,Der Liebe ist nichts unmöglich.' So steht es mit dem ganzen Gewicht einer lateinischen Sentenz auf dem Wagen der Minne in der ,Minnelehre' des

ten des romanischen Mittelalters. München 1972 (Theorie und Geschichte der Literatur und der schönen Künste 28).

16 Karl Bertau: Deutsche Literatur im europäischen Mittelalter. Bd. 2: 1195-1220. München 1973 , S. $1160 \mathrm{ff}$.

17 Johannes Siebert: Der Dichter Tannhäuser. Leben - Gedichte - Sage. Halle/S. 1934, S. $112 \mathrm{ff}$. 
Johann von Konstanz (amori nulla sunt inpossibilia), ${ }^{18}$ einem Werk, das um 1300 den Minnesangdiskurs in eine allegorisch dominierte Erzählung umsetzt und mit der gelehrt-lateinischen Minnetradition zusammenbringt.

Bleiben wir bei den spätmittelalterlichen Minnereden. In der 1404 entstandenen Minnelehre Eberhards von Cersne (,Der Minne Regel') ${ }^{19}$ wendet sich das verliebte Ich an die Königin Minne mit der Frage: ,Wie eloquent muß ich denn sein, um sie zu gewinnen?’ (v. 861f.). Die Antwort der Minne ist abweisend: ,Spar dir das Reden! Jupiter auf seinem Thron lacht über die Schwüre der Verliebten, die wirr sind (wunderlige wort, v. 872) und ohne $\mathrm{Ma}^{\prime}$. Wilde gedanken würden sich ohnehin an keinen orden halten (v. 875f.). Aufs Küssen seien sie aus (Nach kussen ir gedanken stad, v. 890). Aber auf einmal lenkt die Minne doch ein:, Wenn du schon mal da bist', sagt sie, ,Du solltest es so versuchen: „Gehörten mir der Schatz der Nibelungen, das Gold der Griechen, alle Schätze Babylons [...] und das Land Hebron, ich gäbe alles dir, du, Schönste von allen“" (vgl. v. 971ff). Was lernt der Verliebte da? Wenn überhaupt geredet werden soll, dann garantiert Übertreibung den Liebeserfolg. Liebesrhetorik ist Überbietungsrhetorik. Liebe und Übertreibung gehören zusammen, auf der Ebene des Liebesaffekts (wilde minne, wilder gedanc) und der der Darstellung von Liebe (wilde rede). Zur ,hohen' und, süßen' Minne gehören bohes lop (vgl. v. 1003) und suße wordir (v. 1995). Er soll also zu ihr sagen: ,Du bist die Schönste, und ich leide am besten', und w i e das gesagt wird, soll auch am schönsten und besten sein, dauernd wiederholt und - je neu - überboten werden.

Verlassen wir uns ein weiteres Mal auf Selbstauskünfte der Texte. In der bereits zitierten ,Minnelehre' Johanns von Konstanz geht es nicht nur nebenbei, sondern ganz programmatisch darum, wie man nach liebe werben sol (v. 11). Eingeführt als eine am, $\mathrm{Maß}^{\mathrm{c}}$ ausgerichtete rede von minnen (v. 3 und v. 14), schreitet der Text gleichwohl in Übertreibungen voran: Ihre Schönheit setze alle anderen matt (v. 69); hätte Paris sie gekannt, er hätte ihr den Apfel geben müssen (v. 95ff.); ihr roter Mund habe ihn entflammt (v. 109) usf. Vom Pfeil der Liebe getroffen, bettlägrig geradezu, bittet der Ich-Erzähler die Minne um Rat: ,Wie soll ich es ihr sagen?‘ (v. $967 \mathrm{ff}$.). Empfohlen wird dem Leidenden hier eine kultivierte Brief-Rhetorik. Er solle nicht zu viel, nicht zu wenig und vor allem das maßvoll Richtige schreiben, unermüdlich (v. 981ff.). Das tut er. Sein erster dezenter Brief

18 Die Minnelehre des Johann von Konstanz. Nach der Weingartner Liederhandschrift unter Berücksichtigung der übrigen Überlieferung hg. von Dietrich Huschenbett. Wiesbaden 2002, v. 726.

19 Eberhardus von Cersne: Der Minne Regel. Mit einem Anhange von Liedern hg. von Franz X. Wöber. In musikalischer Hinsicht unter Mitwirkung von August W. Ambros. Wien 1861. Nachdruck Hildesheim - New York 1981. 
bewirkt immerhin ihr schamvolles Erröten (v. 1059), aber auch nicht mehr als das. ,Schreib ihr noch einmal', rät die Minne (v. 1170), ,schreib ihr, wie schön sie ist und wie sehr du leidest'. Aber sein zweiter Brief, rhetorisch ambitioniert, macht sie mißtrauisch: ,Wenn er nur halb so viel leidet, wie er behauptet, müßte er längst tot sein' (v. 1255ff.). Auch kein durchschlagender Erfolg. Anders gesagt: Der Zusammenhang von Liebe und Übertreibung ist so ambivalent wie der von minne und mâze.

Sichtbar wird an dieser Stelle, daß mit dem Gestus permanenter qualitativer Überbietung ein Dilemma verbunden ist, und dies keinesfalls nur im Kontext von Minnesang und Minnerede. Wie können einer exklusiven Runde von Schönsten und Besten der Allerbeste und die Allerschönste eingegliedert werden, ohne daß die Übertreibung die andern (schönsten Damen, besten Ritter, besten Erzähler) herabsetzte? Davon erzählt der höfische Roman. Weil der Spielraum innerhalb der Hyperbolik des höfischen Stils eng ist, weil Feste immer die prächtigsten, Pferde immer weiBer als Schnee, schwärzer als Kohle sind und die Damen immer engelgleich schön, müssen die Unterschiede haarfein sein, und auf Dauer gestellt werden kann diese komplizierte Hyperbolik des höfischen Romans nur, indem sie ab und zu, schon bei Hartmann, „mit freundlicher Ironie“ ans Publikum abgegeben wird. ${ }^{20}$

Ein Indiz für das der qualitativen Überbietung eigene Konfliktpotential könnte sein, daß dort, wo der Zusammenhang, die Schönste dem Besten' entkoppelt ist, Gewalt ausbricht. Als Urszene für den ambivalenten Zusammenhang von minne und strît gilt das Urteil des Paris, ein Erzählmotiv, das - die Gattungen querend - aus der Epik schon früh in die Lyrik einwandert (als sogenannte ,mythologische Rollenhypothese ${ }^{221}$ ), zugleich ein so hohes diskursives Potential hat, daß die Szene, etwa in Konrads ,Trojanerkrieg', zu einer Art Minnerede im Roman tendiert: Die von Konrad kunstvoll als wechselseitige Überbietung komponierten Dialogbeiträge im Redewettstreit der drei Göttinnen wirken über weite Strek-

20 Franz Josef Worstbrock: Dilatatio materiae. Zur Poetik des ,Erec ${ }^{`}$ Hartmanns von Aue. In: Frühmittelalterliche Studien 19 (1985), S. 1-30, hier S. 25. Daran anknüpfend Hans Jürgen Scheuer: Gegenwart und Intensität. Narrative Zeitform und implizites Realitätskonzept im ,Iwein' Hartmanns von Aue. In: Zukunft der Literatur - Literatur der Zukunft. Gegenwartsliteratur und Literaturwissenschaft. Hg. von Reto Sorg, Adrian Mettauer und Wolfgang Pross. München 2003, S. 123-138, hier S. 127f. (die Funktion der Hyperbolik höfischen Stils als „Äquilibristik“ „,intensiver Größen“ erläuternd). Vgl. außerdem Karl Bertau: Der Ritter auf dem halben Pferd oder Die Wahrheit der Hyperbel. In: PBB 116 (1994), S. 285-301. Weniger ergiebig dagegen: Alexander García Düttmann: Philosophie der Übertreibung. Frankfurt/M. 2004.

21 Dazu Rudolf Wilhelm Lenzen: Überlieferungsgeschichtliche und Verfasseruntersuchungen [sic] zur lateinischen Liebesdichtung Frankreichs im Hochmittelalter. Diss. Bonn 1973, S. $20-22$. 
ken traktathaft-belehrend;22 wie auch umgekehrt Konrads Descriptio der unwahrscheinlichen Schönheit Helenas (eine im Vergleich mit den Vorlagen breit expandierende Überbietungstopik) in zwei Handschriften des 15. Jahrhunderts separat überliefert ist als Minnerede unter Minnereden. ${ }^{23}$ Diese Gattungsübergängigkeit gilt es im Auge zu behalten.

Mein Anlauf war lang. Aber die Frage, was Übertreibung ist, als was sie galt, gehörte an den Anfang meiner Überlegungen. Aus ihnen ging hervor: Übertreibung ist eine Form sprachlicher Hervorhebung (Emphasis). ${ }^{24} \mathrm{Wie}$ ihr Nachbartropus, die Metapher, ist sie ein imaginatives Verfahren, ein grenzüberschreitend-erfinderisches, das den Gegenstand aus seinen (lebensweltlich, handlungsweltlich) realen, aus seinen buchstäblichen oder konventionellen Bezügen emphatisch herauslöst und mit jeweils neuer Bildintensität, vor Augen stellt. ${ }^{25}$ Aus ihrer Zwischenstellung zwischen „Wahrheit" und „Lüge" rührt die Ambivalenz der Hyperbel. Die Übertreibung „lüge“ durchaus, gesteht Quintilian zu, ,aber nicht so, daß sie betrügen will“ (nec ita, ut mendacio fallere velit, 8,6,74). Für die eingebüßte Glaubwürdigkeit der Übertreibung entschädige die Aktivierung der Einbildungskraft, genauer: eine Überschußqualität über das hinaus, was ist (plus quam in re) oder wahr ist (ultra veritatem rel). Somit ergibt sich ein für hyperbolisches Sprechen konstitutiver Zusammenhang von I $\mathrm{m}$ a g i n a tion, Maß herstellender Reflexion und dabei durchaus gewahrter Anschlußfähigkeit für $\mathrm{N}$ a r r a ti o n. Auf eine Figur bloßer Substitution kann Übertreibung nicht von vornherein festgelegt werden. ${ }^{26}$ Ob sie ein im angedeuteten Sinn projektives, grenzüberschreitendes Verfahren ist oder im Gegenteil bloßer Leerlauf, diese Frage nach der Funkti-

22 Zuletzt Gert Hübner: Lobblumen. Studien zur Genese und Funktion der ,Geblümten Rede`. Tübingen - Basel 2000 (Bibliotheca Germanica 41), S. $129 \mathrm{f}$.

23 V. 19661-20054; dazu der Hinweis bei Wolfgang Achnitz: Kurz rede von guoten minnen/ diu guotet guoten sinnen. Überlegungen zur Binnendifferenzierung der sogenannten, Minnereden'. In: Jahrbuch der Oswald von Wolkenstein-Gesellschaft 12 (2000), S. 137-149, hier S. 147 (mit Bezug auf Tilo Brandis). Zur Gattungsmischung vgl. Cora Dietl: Minnerede, Roman und historia. Der, Wilhelm von Österreich' Johanns von Würzburg. Tübingen 1999 (Hermaea N.F. 87); Rüdiger Schnell: Grenzen literarischer Freiheit im Mittelalter. I. Höfischer Roman und Minnerede. In: ASNS 218 (1981), S. 241-270.

24 Vgl. Georg Michel: Emphase. In: RLW 1 (1997), S. 441-443 (u. a. mit Blick auf Hyperbel und Ironie).

$25 \mathrm{Zu}$ dieser rhetorischen Kategorie vgl. Rüdiger Campe: ,Vor Augen stellen`. Über den Rahmen rhetorischer Bildgebung. In: Poststrukturalismus. Herausforderung an die Literaturwissenschaft. Hg. von Gerhard Neumann. Stuttgart - Weimar 1997 (Germanistische Symposien. Berichtsbände 18), S. 208-225.

26 So etwa, das „terminologische Feld“ der Rhetoriktradition resümierend, Michel (Anm. 24), S. 442: „Hyperbel: Ersatz einer usuellen Bezeichnung durch einen inhaltlich übertreibenden Ausdruck." 
on und ästhetischen Qualität der Übertreibung muß für jeden Einzelfall gesondert angegangen werden.

Mein Ausgangspunkt war eine hyperbelkonstitutive Verbindung von Imagination, Maß herstellender Reflexion und Narration. Mit eben dieser Verbindung scheint Hyperbolik eine hohe Attraktion für die ab $1300 \mathrm{im}$ deutschen Sprachgebiet einsetzende Textgattung Minnerede zu haben. Zwischen allen Sprechweisen angesiedelt, zur Seite des Minnelieds wie des Romans hin offen, sind Minnereden in verschiedener Hinsicht eine hochintegrative Gattung, deren anhaltende Beliebtheit daraus erklärbar ist, daß sie das problemüberschüssige ,alte` Minnethema neu aufladen. Mit ihrer auffälligen Integrationsfunktion treten sie nach vorne in dem Moment, als die Minnelyrik, thematisch und überlieferungsgeschichtlich benachbart, einen anderen (engeren) Weg einschlägt als bisher. ${ }^{27}$ Mit ihrer Grenzposition zwischen Lyrik und Epik, auch mit ihren flexibel wechselnden Anteilen buchstäblicher wie übertragener Redeweise wirkt die Gattung Minnerede einerseits experimentierfreudig. Anderseits verhält sie sich in hohem $\mathrm{Maße}$ traditionskonform. Diese Gleichzeitigkeit einer Attraktion und Erschöpfung des Minnethemas in den spätmittelalterlichen Minnereden ist irritierend. Mich führt sie zu der Überlegung, daß gerade die Hyperbolik ein privilegiertes und geschätztes Mittel gewesen sein könnte, i n n e r $\mathrm{h}$ a l b der strengen Konventionsbindung der Minne-Literatur Profil zu zeigen. Die amplifikatorische Übertreibung von Bekanntem (von rhetorischer, literarischer Konvention) wäre nach der einen Seite die trostlose Stereotypie der Gattung Minnerede. Umgekehrt will die Übertreibung das Bekannte qua Konventionsbruch ja gerade exklusiv machen; das wäre nach der andern Seite ihre schier unerschöpfliche Attraktion. Wie ein solches Zusammenspiel von Konvention und Konventionsbruch genau funktioniert, wie der von mir allgemein angesetzte Zusammenhang von Imagination, Reflexion und Narration für die Minnereden und ihre (virtuose? monotone?) ,Kunst der Überbietung' spezifisch wird, das möchte ich im folgenden anhand einer Konstellation von Texten beschreiben, die um ein hochkonventionalisiertes rhetorisches Detail gruppiert sind: um die hyperbolische Metapher vom rosenroten, feuerroten, blutroten, alle Röte überbietenden roten Mund. Der ,rote Mund' ist ein DescriptioDetail, mit dessen vorgegebener, schon hochmittelalterlicher Hyperbolik die spätmittelalterlichen Autoren ihr eigenes Spiel treiben, ein DescriptioDetail, in dem die beiden eingangs angesprochenen Mittelpunktthemen des höfischen Minnediskurses - Liebe als Affekt und Liebe als Sprache zusammenfallen.

27 Der Minnediskurs verschiebt sich auf die Minnerede. Darauf hat bereits Ingeborg Glier hingewiesen: Artes amandi. Untersuchung zu Geschichte, Überlieferung und Typologie der deutschen Minnereden. München 1971 (MTU 34). 
Mich interessieren Formen und Funktionen der ,Roter Mund'Hyperbel. Fragen der Wertung stelle ich zunächst zurück. Erst zum Schluß versuche ich, von meinen exzentrischen Beispielen aus, die Frage aufzunehmen, ob und wie wir einen Zusammenhang von ,Konventionalität ${ }^{c}$ und ,Trivialität ${ }^{c}$ herstellen können in einer Epoche, in der Erneuerung an formschaffendes Vermögen gebunden ist, so $\mathrm{da} ß$ von vornherein die Gleichung ,Konventionalität=Trivialität' nicht funktionieren kann.

\section{Unter Ironieverdacht: ,Der rote Mund“}

Wie alle Tropen sind auch Übertreibungen der Gefahr der Abnutzung ausgesetzt. Die Gewöhnung an Übertreibung verdirbt das Mittel. Tote Hyperbeln gibt es deswegen so viele wie tote Metaphern. Mausetot scheint im Spätmittelalter die Hyperbel vom, alle Röte übertreffenden roten Mund' der Geliebten.

Im folgenden liste ich verschiedene Erscheinungsweisen dieser $\mathrm{Hy}$ perbel auf, ohne Anspruch auf Vollständigkeit, aber mit dem Interesse einer Dokumentation von Vielfalt. Denn der Modus qu a n t it a t iv e r Verbreiterung - Übertreibung als Mittel der dilatatio/amplificatio kann abgehoben werden von Übertreibungen qua Übe rtrag ung (per similitudinem, per comparationem, per translationem: hyperbolischen Gleichnissen, Vergleichen, Metaphern), ${ }^{28}$,Übertragungs-Übertreibungen' also, die die Spannung zwischen Verbum proprium und Verbum translatum unterschiedlich rasch abbauen können, so daß dieser Modus seinerseits noch einmal binnendifferenziert werden kann. Weil obendrein Übertreibungen Übertreibungen anziehen, weil Hyperbeln, wie Quintilian sagt $(8,6,68-70)$ „wachsen“, nämlich ins immer Unwahrscheinlichere, haben sie außerdem eine Tendenz zur Ironie.

(1) Ich beginne meine improvisierte Reihe mit dem einfachen Fall von Motivwiederholungen. Für wiederholungsrhetorisch generierte Hyperbolik kann Gottfried von Neifen stehen, in dessen Liedern, die auf allen Ebenen hochrepetitive Strukturen aufweisen, der rote Mund als eine Art Autorsignatur eingesetzt ist; ${ }^{29}$ häufig personifiziert, nicht selten auch als

28 Quintilian (Anm. 1), 8,6,68f.

29 Vgl., auf zehn Lieder verteilt, die Belege bei Claudia Händl: Rollen und pragmatische Einbindung. Analysen zur Wandlung des Minnesangs nach Walther von der Vogelweide. Göppingen 1987 (GAG 467), S. 277, Anm. 119 und auch S. 283. Hugo Kuhn zählt den ,roten Mund' $28 \mathrm{Mal}$ in 190 Strophen: Minnesangs Wende [zuerst 1952]. 2., vermehrte Aufl. Tübingen 1967 (Hermaea N.F. 1), hier S. 72, Anm. 57. 
metonymischer Phraseologismus ${ }^{30}$ auf der Stufe von mîn lîp=ich: ,Sprich ja, lache, roter Mund!‘. Bei Neifen kann sich das Signalwort ,rot ${ }^{`}$ auf andere Minnesang-Leitwörter so weit ausdehnen (roter Gruß, roter Kuß), daß - über den einfachen Fall einer Enallage hinaus - Spannungen aufkommen zwischen buchstäblicher und übertragener Ausdrucksweise.

Frauenlobs Lied 2, dessen Klagegestus auf den ersten Blick konventionell wirkt, setzt genau hier an. ${ }^{31}$ Es häuft unüberhörbar NeifenMaterial. Gleich zu Beginn fällt das erotische Signalwort ,roter Mund': ,Wanne sol din roter munt mich lachen an [...]? (v. 6,5). Angesichts der Röte ihres Mundes bleibe den Rosen nur zu kapitulieren (Sprechet alle, rote rosen, I daz ein munt mit roten siget, v. 7,3f.). Diesen Wettstreit nimmt u.a. die Genitivmetapher Diner lüste rosen auf (v. 8,5), über die das Lied eine erotische Spannung aufbaut. Der Abgesang der vierten Strophe bringt einen neuen Überbietungsgestus, den zweiten nach dem Rotsein-Wettbewerb: ,Ich leide mehr als Iwein', und die letzte Strophe präsentiert eine dritte Konkurrenz. In der hypothetisch angesetzten Rolle des Paris formuliert das Ich einen Rachewunsch: ,Hätte ich den Apfel des Paris zu vergeben, ich enthielte ihn dir, Minne/Venus, vor'.

(2) In diese Reihe gehören zweitens adjektivische Kompositmetaphern wie ,rosenrot', ,rubinrot', ,feuerrot', unauffällige Komposita, die gattungsund autorübergreifend weit verbreitet sind. Ihnen gegenüber wirkt die

30 Weiterführend dazu Harald Haferland: Das Mittelalter als Gegenstand der kognitiven Anthropologie. Eine Skizze zur historischen Bedeutung von Partizipation und Metonymie. In: PBB 126 (2004), S. 36-64, bes. S. 44ff. Metonymie wird hier umfassend als kognitive Operation aufgefaßt und so verallgemeinert, daß Haferland auch von ,narrativer Metonymie" sprechen kann (S. 55), außerdem - über die Kategorien ,Kontiguität" und ,Partizipation $^{\text {‘ }}$ - den Bogen von sprachlichen Sachverhalten zur (rituellen, magischen) Praxis schlagend, den Begriff zum Schluß (Anm. 78) auf einer Metaebene metaphorisch entgrenzt einsetzt (Willehalms Schwertgeste sei „geradezu eine Metonymie der Bereitschaft zum Handeln"). In Bezug auf Wolfram textanalytisch ergiebig: Stephan Fuchs-Jolie: Die Gleich-Gültigkeit des Möglichen. Wege zu einer nicht-fragmentarischen Poetik von Wolframs ,Titurel'. Habilitationsschrift masch. 2003, bes. S. 18ff. ,Metapher, Metonymie und Mikrostruktur' (erscheint demnächst bei de Gruyter). Grundsätzlich dazu: David E. Wellbery: Übertragen: Metapher und Metonymie. In: Literaturwissenschaft. Einführung in ein Sprachspiel. Hg. von Heinrich Bosse und Ursula Renner. Freiburg/Br. 1999 (Rombach Grundkurs 3), S. 139-155.

31 Frauenlob (Heinrich von Meissen): Leichs, Sangsprüche, Lieder. Auf Grund der Vorarbeiten von Helmuth Thomas hg. von Karl Stackmann und Karl Bertau. 2 Teile. Göttingen 1981 (Abhandlungen der Akademie der Wissenschaften in Göttingen. Philol.-hist. Klasse. 3. Folge 119/120), XIV,6-10. Zu diesem Lied Verf.: Frauenlobs Lieder. Parameter einer literarhistorischen Standortbestimmung. Tübingen - Basel 2003 (Bibliotheca Germanica 43), S. $58 \mathrm{ff}$. 
Adjektivbildung bei Ulrich von Liechtenstein: chleinvelbitzeroter süezer munt, geradezu monströs. ${ }^{32}$

(3) Drittens finden sich Überbietungs-Vergleiche des Typs, röter als .... Sie kombinieren die Farbe Rot häufig mit anderen Farben. Lieblingsklischee ist die Verbindung, lilienweiß und rosenrot ${ }^{6}{ }^{33}$ Die übertreibungsanfällige Variationsanstrengung des Spätmittelalters belegt Anfang des 14 . Jahrhunderts die ,Minneburg', die den rhetorisch konventionellen ,rotweiß'-Kontrast wie folgt aufgreift: Alle Königreiche gäbe ich für sie hin. Nie kann ich zur Ruhe kommen, es sei denn, sie tröstete mich, „meine Zucker-Traube, die glänzt wie eine rote Rübe, die mit Milch übergossen ist" (Mich troste dann min zucker trúb | Die do sam ein rote rúbe | Glentzet, die mit milch begoßen | Ist [...]).34 Auf der Hand liegt, daß solch exzessive Vergleiche sich hier zusätzlich sprachlich-klanglich verselbständigen, eine nicht zuletzt reimgesteuerte Sprachklangfaszination, der gegenüber die regulative Kraft der Ratio zu versagen scheint.

(4) Wiederum in der ,Minneburg' stößt man auf eine in enger Folge geschaltete Serie von ,Roter Mund'-Variationen. Ich nenne zum einen (a) eine steigernd angeordnete Folge hyperbolischer Vergleiche: Ihr roter Mund leuchte heller als ein Blitz, heller als die Sonne, ja Gottes Pinsel selber müsse ihn gemalt haben (v. 3406ff.); wollte man das lop ihrer Schönheit nur halbwegs aufschreiben, ein Wagen würde zusammenbrechen unter der Last des Geschriebenen (v. 3460ff.); zum andern (b) eine tierallegorische Erweiterung des ,Roter Mund'-Topos: Ihr roter Mund erwecke sein totes Herz wieder zum Leben, so wie das Brüllen des Löwen dessen tote Kinder verlebendige (v. 3485ff.); drittens (c) eine narrativepisodische Erweiterung: Meister Arnold von Würzburg könne darauf verzichten, rote Farbe zu kaufen. Er halte nur seinen Pinsel an ihren roten Mund und verfügt schon für die Dauer eines ganzen Jahres über rote Farbe:

\section{[...] Er nem núr sin pensel rein \\ Und habt in an iren roten munt: \\ $\mathrm{Zu}$ bant und an der selben stund}

32 Ulrich von Liechtenstein: Frauendienst. Hg. von Franz Viktor Spechtler. Göppingen 1987 (GAG 485), Lied 41, Str. 5, v. 6.

33 Vgl. zur literarischen Tradition der,Lilien und Rosen' die Stellensammlung bei Werner Fechter: Lateinische Dichtkunst und deutsches Mittelalter. Forschungen über Ausdrucksmittel, poetische Technik und Stil mittelhochdeutscher Dichtungen. Berlin 1964 (Philologische Studien und Quellen 23), S. 48-61.

34 Die Minneburg. Nach der Heidelberger Pergamenthandschrift cpg 455 unter Heranziehung der Kölner Handschrift und der Donaueschinger und Prager Fragmente hg. von Hans Pyritz. Berlin 1950 (DTM 43), v. 4745-4748. 
So vil der rote dar in scbúße,

Daz ein gantzes jar dann fluße

Paris varb genug dar us. 35

Die an dieses Lob anschließende Klage (v. 4516ff.) will ausdrücklich den Übertreibungsspezialisten Wolfram überbieten: Ich leide schlimmer als Sigune, Willehalm und Amfortas zusammengenommen (v. 4532ff.). (Die Wolfram-Imitatio der spätmittelalterlichen Minnereden, wie sie auf ganz verschiedenen Ebenen stattfindet, ist ein eigenes, unerledigtes Thema.)

(5) Metonymisch gestörte ,Roter Mund'-Metaphern, wie Wolfram sie liebt, sind ein komplizierter Sonderfall; auf sie komme ich unten zurück.

(6) Das ,Roter Mund'-Motiv erscheint häufig in fester Verbindung mit den Augen; so bei Morungen (z.B. MF 130,27ff.), insbesondere mit perspektivisch verschobenem, gespaltenem Subjekt: meine Augen und d e in roter Mund haben mich verletzt $t^{t}$. Irritierend allegorisch gebrochen und zugleich ,real' ist Morungens berühmte Modifikation des roten Mundes im Narzißlied, das den Mund (dessen Rotsein) mit Blut in Verbindung bringt (MF 145,1). Sowohl den feuerroten wie den rosenroten Mund kombiniert eine Morungen-affizierte Minnerede aus der LosseSammlung ${ }^{36}$ :

Do sach ich manegen roden münt,

der stuint recht, als er were inzunt

von lechte [r] flammen fure;

[...]

sozir stemme nye gesanc

so [uv] einen muinde erclanc,

$d[$ er] bran recht als ein(e) roselin,

daz in deme meyen gebit schin,

wanne iz in dem dowe ufgat,

da iz bi gronen love stad.

(7) Als ,rot-weiß'-Kontrasttopos innerhalb von Schönheits-Descriptiones ist der rote Mund in der höfischen Epik allgegenwärtig. Eine Schlüsselszene ist Enites Auftritt am Artushof, der bei Hartmann alle Ritter erschrecken läßt ihrer unwahrscheinlichen Schönheit wegen. ${ }^{37}$ Enites schamvolles Erröten wird mit Rosen und Lilien zusammengebracht, ihre

35 Ebd., v. 4472-4477.

36 Zwölf mittelhochdeutsche Minnelieder und Reimreden. Aus den Sammlungen des Rudolf Losse von Eisenach. Hg. von Edmund E. Stengel und Friedrich Vogt. In: Archiv für Kulturgeschichte 38 (1956), S. 174-217, hier S. 211, Nr. 11, v. 108ff.

37 Hartmann von Aue: Erec. Hg. von Albert Leitzmann, fortgeführt von Ludwig Wolff. 6. Aufl. besorgt von Christoph Cormeau und Kurt Gärtner. Tübingen 1985 (ATB 39), v. $1698 \mathrm{ff}$. 
leuchtende Schönheit in eine aufsteigend angeordnete Reihe farbästhetisch akzentuierter Vergleiche gefaßt (v. 1701ff.). Hartmann brilliert hier mit einer amplifikatorischen Übertreibung, die "nicht nur sich meint", sondern funktionstragend wird, indem sie Enites Schönheit als Rangkriterium aufbaut, worauf - im Blick auf Chrétien - Worstbrock hingewiesen hat. ${ }^{38}$

Man sieht, welch breites Spektrum vertreten ist, nach beiden Richtungen quantitativer Verbreiterung und qualitativer Übertragung, dies durchaus gattungsübergreifend.

Am äußersten Rand des oben improvisierten Spektrums steht eine Minnerede, in der die ,Roter Mund'-Hyperbel über mehrere hundert Verse hin zum kuriosen Mittelpunktthema aufsteigt. Sie interessiert mich im folgenden. Wohl aus dem frühen 14. Jahrhundert stammend, ${ }^{39}$ ist sie in zwei Sammelhandschriften des 15. Jahrhunderts überliefert. ${ }^{40}$

Meine Beobachtungen folgen der 361 Verse umfassenden (Lang-) Version im Codex Karlsruhe 408, einer um 1430 wohl im Ostfränkischen entstandenen Sammlung von 114 Reimpaardichtungen mittleren Umfangs, überwiegend Mären, Fabeln, Tugendlehren, aber auch Minnereden. An 85. Stelle, in der Nachbarschaft anderer Minnereden, steht: Von der schonsten frawen genant $\mid$ der rot munt.

$\mathrm{Daß}$ sie mit einer Hyperbel beginnt, wird nicht verwundern: ,Alle Frauen, die ich je gesehen habe, sind ein Schlag in einen Bach gegen sie, die eine, die ich jetzt gesehen habe. ${ }^{{ }^{4} 1}$ Überbietung, damit hatte ich begonnen, schließt die Überbietung der literarischen Tradition ein. Deswe-

38 Worstbrock (Anm. 20), hier S. 6-9.

39 Vgl. Ingeborg Glier: ,Der rote Mund'. In: 2VL 8 (1992), Sp. 264f.; Glier (Anm. 27), S. 118121. Unter dem Aspekt einer von verschiedenen „Präsenzeffekten“ gestützten „Ablösung des Phänomenalen vom Diskursiven" hat Michael Waltenberger diese Minnerede vor kurzem analysiert: Diß ist ein red als bundert. Diskursive Konventionalität und imaginative Intensität in der Minnerede Der rote Mund. Ich danke ihm herzlich für die Überlassung des Typoskripts. Der Aufsatz ist mittlerweile erschienen in: Visualisierungsstrategien in mittelalterlichen Bildern und Texten. Hg. von Horst Wenzel und C. Stephen Jaeger in Zusammenarbeit mit Wolfgang Harms, Peter Strohschneider und Christof L. Diedrichs. Berlin 2005 (Philologische Studien und Quellen 195), S. 248-274.

40 Codex Karlsruhe 408 und (die kürzere Version) cgm 714. Text der längeren Version in: Codex Karlsruhe 408. Bearbeitet von Ursula Schmid. Bern - München 1974, S. 503-512; vgl. auch die ältere Edition: ,Die altdeutsche Erzählung vom rothen Mundé. Hg. von Adelbert von Keller. In: ders.: Verzeichnis der Doctoren, welche die philosophische Facultät in Tübingen im Decanatsjahre 1873 bis 1874 ernannt hat. Tübingen 1874, S. 8-20. Die Minnerede erscheint als Nr. 1 bei Tilo Brandis: Mittelhochdeutsche, mittelniederdeutsche und mittelniederländische Minnereden. Verzeichnis der Handschriften und Drucke. München 1968 (MTU 25).

41 Was ich frawen ye gesach, | Daß ist als eyn slack in ein bach | Wider eyn, die hon ich nu ersehen. (v. 1-3). 
gen kommt unsere Minnerede schon in Vers 6 bei Wolfram an, der, auch das wenig überraschend, mit einem Superlativ eingeführt wird: ,Er, der Frauen so rühmen konnte, daß keiner ihm darin überlegen war' (v. 9f.) oder, je überlegen sein wird' (Die werlt also ver brynt, $\mid$ daß nymmer sein gleich wirt, | Er hot ir aller lob ver irt, v. 16-18). Sodann läßt der Erzähler eine ganze Schar schönster Frauen aus Wolframs ,Parzival' Revue passieren: Beaflur, Orgeluse, Condwiramurs, Repanse de Schoye, Jeschute, Cunneware, und übertrumpft im selben Atemzug diese Schönheitsgalerie: ,Hätte Wolfram meine Dame gesehen, er hätte sie alle stehenlassen und, bei meinem Leben!, getobt hätte er, d.h. jedes Maß verloren. ' ([...] Bey namen er wolt dan toben; | Er bulff mir die ßusen loben | Mit red vnd mit schalle | Endlich fur sie alle, v. 35-38). Der Reim toben: loben (v. 37f.) kann für den hier vorgeführten und, wie wir sehen werden, auch besprochenen Sprechakt, hyperbolisches Lob' (hohes lop, v. 30) als ein Schlüsselreim gelten. Es handelt sich um eine stereotype, andernorts in der Regel negativ besetzte Reimverbindung ${ }^{42}$ wohingegen die inhaltlich naheliegende Reim-Kombination rüemen : blïemen in der zeitgenössischen Literatur kontextabhängig negativ o d e $\mathrm{r}$ positiv konnotierbar ist (rüemen kann, muß aber nicht den Verdacht des Maulheldentums transportieren); wieder anders das Reimpaar zieren : florieren, das wertneutral scheint. Die genannten Signalreime, auch wenn systematische Untersuchungen ausstehen, belegen eine graduelle Skala. Zu ihr paßt die gleitende Synonymik der Rhetoriken (excessus ad uberantiam, aber: redundantiam denotat byperbole, so oben Scaliger). Dies alles zusammengenommmen zeigt einmal mehr, daß die Grenze zwischen rhetorischer Abundanz und Redundanz fließend ist.

Zurück zur Minnerede. ,Aber ach!', fällt das Ich sich ins Wort, ,Wolfram ist tot. Dann lob' ich sie eben': Der ist do [n] hin, das mag nit sein; | So lob ich doch die frawen meyn (v. 44f.). Vierzig Verse hat es gedauert, bis der Erzähler wieder bei sich und seiner Schönsten ist. Was nun folgt, ist eine Reihe sich überschlagender Übertreibungen.

Den Anfang macht eine Hyperbel im Irrealis, die sich über fast dreißig Verse ausbreitet: ,Jeder, der sie gesehen hätte, müßte zugeben, sie ist die Schönste (v. 47-73). Dem folgt eine Hyperbel, die wie ein dreigliedriger Syllogismus gebaut ist und, biblisch inspiriert (Is 30,26), mit dem Kontrast ,Diesseits/Jenseits' arbeitet: 1. Prämissa maior: Im Jenseits seien die Menschen sieben Mal schöner als die Sonne. 2. Prämissa minor: Sie, die Lieb-

42 Nur drei Beispiele: Hartmann von Aue: Klagebüchlein. Hg. von Ludwig Wolff. München 1972 (Altdeutsche Texte in kritischen Ausgaben 4), v. $1512 \mathrm{ff} .:$ [...] gibt aber iemen, wie der tobet $\mid$ daz er sî über mâze lobet', | der selbe ist âne rebten sin [...]; Johann von Konstanz (Anm. 18), v. 1833f.: ach geselle, wie du tobest, | daz du mir minne also lobest [...] ; außerdem die Variation der ,Minneburg' (Anm. 34), v. 4398ff., die den stereotypen Reim auffallig ausspart: $I c b$ wird da von unsynnig | Und tobig in dem birne, | Wenn ich daz selbe durch kime [...]. 
ste, sei schon hier, im Diesseits, schöner als die Sonne. 3. Conclusio: Wie schön wird sie erst dort, im Jenseits, sein, etc. (v. 74-84). Der nächste Superlativ greift auf Gott zurück (er habe sie als sein vollkommenstes Geschöpf geschaffen, v. 86ff.). Da hält der Erzähler inne: Wollte ich alle ihre Körperteile angemessen würdigen, dann längte ich meine Geschichte (v. 90ff.). Die rhetorische Konvention einer umfassenden Descriptio personae ist damit beiseitegeschoben. Warum, sagt er auch gleich, im nächsten Vers: Diß ist ein red als bundert. Hundert Mal sei das alles schon gesagt worden, daß sie singulär schön sei, schöner als schön:
Lobt ich yeklich ir gelit,
Hie lengert ich daß mer mit.
Diß ist ein red als hundert:
Ir schon ist aus gesundert,
Daß ich gar boch wil keronen
Ir schon vber alle schone. (v. 90-95). ${ }^{43}$

Ist dies ein Fall besprochener, gewußter Trivialität? Wir sollten unvoreingenommener sagen: gewußter Konventionalität. Jedenfalls ist der Reim v. 92f. überraschend, weil er die Exklusivität (aus gesundert) mit der Konventionalität (ein red als bundert) so eng koppelt.

Jetzt muß er es also anders machen, wenn er weitermachen will. Er versucht es so: Sie ist mein "Heiligtum ${ }^{\prime}$ - das ist aber schon wieder ein Topos. Die Neuerung besteht im komischen Wörtlichnehmen (v. 96ff.): Die Wallfahrer und Rompilger, die sich's gut gehen lassen und sich den Wanst vollschlagen, wenn die das für ehrenvoll halten, daß man sie bestreigt mit heylgtum (v. 101), die täuschen sich. Haben sie doch nur tote Knochen (toten bein). Dagegen sein Heiligtum erlöse wahrlich von allem Unheil (von vnselden, v. 108). Denn jenes - die heiligen Knochen - spricht ja nicht, dieses aber - ,mein süßes Gesicht ${ }^{c}$-, es spricht, hört, sieht und lächelt liebevoll (v. 112ff.). In meinen Ohren klingt das wie eine WaltherAnspielung (wie ein schwaches Echo auf 66,2144).

43 Man könnte sich auch eine andere als die in der Ausgabe von Schmid (Anm. 40) vorgeschlagene Interpunktion denken (einen Punkt statt des nach vorne öffnenden explikativen Doppelpunkts in v. 92). Dann ergäbe sich ein Kontrastargument: „Ihre Schönheit ist dagegen so exklusiv $[\ldots]^{\text {“c. }}$.

44 Walther von der Vogelweide: Leich, Lieder, Sangsprüche. 14., völlig neubearbeitete Aufl. der Ausgabe Karl Lachmanns. Hg. von Christoph Cormeau. Berlin - New York 1996, 67,32:

Ich bâte ein schane bilde erkorn.

und owê, daz ichz ie gesach

und ouch sô vil zuo ime gespracb! eq bât schane und rede verlorm.

$D a ̂$ was ein wunder inne, daz fuor ich enweiz war.

dâ von gesweic daz bilde iesâ.

sîn lilienrôsevarve [!] wart sô karkervar,

daz eq verlôs smac unde schin. [...] 
Nun folgt erneut eine Passage, die sich einige Zeit auf der Metaebene aufhält. Die Kritik trifft diesmal nicht die ausladende Descriptio-Technik insgesamt, sondern eine konkrete Schmuckfigur, die wir schon kennen: den Rosen-Lilien-Tropus. Der sei kindisch, einfallslos, allenfalls eine Notlösung:
Sprech ich, das die frane mein
Het liligen weis und rosen schein,
Die red wer ein teil ze grob,
Wann rosen ist der kind lop,
Oder der nit weger $\beta$ vinden kan,
Man seczt ein rosen dort bin dan.
So es sey inder rosen zeyt
$\checkmark$ nd als das felt mit rosen leyt,
$V$ nd so sie vor dem tan auff gen
$V$ nt spilent in rechter rot sten [...] (v. 116-125).

Im Anschluß folgt - der Erzähler muß es ja besser machen - ein hyperbolischer Vergleich, der über zwanzig Verse ausgreift: Selbst das Rot einer Rose, die das Rot aller Rosen auf sich vereinte, so daß sogar ihre Staubfäden rot wären, selbst diese rose cluck müßte verblassen angesichts der flammenden Röte ihres Mundes, den Gott selbst entzündet habe (v. 125148).

Allmählich geht dem Autor beim Übertreiben die Luft aus. Er setzt neu an und kündigt die Erzählung eines großen Wunders an (v. 155). Scharnierstelle sind die Verse 150-153, die die Autorität der Literatur und die der Augenzeugenschaft nebeneinanderstellen (pointiert im Reim: von rot iehen: selber gesehen, v. 150f.). Genaugenommen folgen zwei Wundergeschichten, ein groß wunder und ein aller grost wunder (v. 172); das Prinzip steigernder Wiederholung greift demnach auch in der Makrostruktur des Textes. Zunächst das, große $\mathrm{e}^{\mathrm{C}}$ Wunder: Ihr Mund sei so herausragend rot, daß seine Röte auf die Münder aller, denen sich ihr Gebet zuwendet, abfärbe (v. 155-164). Dieses groß wunder zieht sogleich zwei Wahrheitsbeteuerungen nach sich: Es ist wor, gelaubt mir (v. 165), und: Es ist wor, ich hons gesehen (v. 167). Das zuletzt beanspruchte Argument der persönlichen Augenzeugenschaft, das die eingangs beschworene fremde Augenzeugenschaft - als hypothetische: ,wenn Wolfram sie gesehen hätte ... - nun überbietet, löst den Bericht des zweiten ,allergrößten Wunders' aus. Erzählt wird die folgende Geschichte: Sie, die Schönste, kniet vor dem Altar in der Kirche, in der Hand einen Psalter. Der Erzähler ist ganz in ihrer Nähe, so nah, daß er in ihrem Psalter mitlesen kann (hier ist eine dritte Wahrheitsbeteuerung eingeschoben: Es ist wor, gelaubt mir, v. 180). Da sieht

Vgl. dazu Jan-Dirk Müller: Walther von der Vogelweide: Ir reinen wîp, ir werden man. In: ZfdA 124 (1995), S. 1-25. 
er, daß sich die schwarze Tinte der Notenschrift rot färbt. Auch das weiße Pergament färbt sich rot, das es den augen rot bot (v. 191) - ein unüberhörbares Wolframzitat ${ }^{45}$-, die weißen Wände stehen in Flammen, die Kirchenfenster brennen rot, brennen bis heute noch: ein Wunder. Zum Erstaunen des Ich liest sie, die Schöne, ganz ungerührt weiter im Psalter, laut, und zwar, nicht ohne erotischen Doppelsinn, die Psalm-Worte: ,Herr, öffne meine Lippen' (Domine labia mea aperies, v. 204; vgl. Ps. 50,17). ${ }^{46}$ Der Psalter glänzt daraufhin in ihren weißen Händen, röter als die Sonne am Ostermorgen: [...] Rotter dann der sunden schein, | Als sie an dem ostertag auff get I Vnd spilent in rechter rot stet (v. 207ff). Diese Formulierung gibt deswegen zu denken, weil der Autor, der in seinem oben zitierten metaphernkritischen Einschub (v. 124f.) den ,rosenrot-lilienweiß'-Topos als trivial gebrandmarkt hatte, im Blick auf diesen Vers seines eigenen Gedichts allen Grund hätte, sich zu beschweren. Die Formulierungen sind dieselben, hier wie dort, womit der Autor sich ein wenig die Pointe verdirbt. Jedenfalls, das Ich kann nur noch an Rot denken. Der Psalter geht in Flammen auf, und alle, die in ihrer Nähe stehen, sind geert und gewirdet (v. 241f.). Bei v. 243 ist dann Schluß: Das kan ir munt, der frawen myn. Aber es folgen noch gut hundert Verse. Das hyperbolische Lob weicht einer hyperbolischen Klage (leyt vor allem leyt, v. 294): Sie versagt ihm den Gruß. Trotzdem will er ihr beständig dienen. Unüberhörbar übernimmt die Minnerede mit dieser Doppelung der Sprechakte ,Frauenpreis' und ,Kla$\mathrm{ge}^{\epsilon}$ ein prominentes Minnelied-Strukturmodell. Ganz zum Schluß ist immer noch nicht Schluß. Der Erzähler wendet sich an sein Publikum, zunächst mit einer (letzten) Wahrheitsbeteuerung: ,Frauen, Mädchen, Männer, ihr denkt, ich scherze?‘ ([...] Ir went leicht, es sey myn spot? | Es ist wor, summer got!', v. 320f.), dann mit einem Appell: ,Ihr habt mir aufmerksam zugehört. Jetzt seid ihr dran! Ich kann schweigen.' (v. 348ff.) Damit ist abschließend die - unabschließbare - Hyperbolik ans Publikum delegiert. ${ }^{47}$

45 Das phantastische Rotsein von Ithers Rüstung wird eingeleitet durch die Verse: Sîn harnasch was gar sô rôt $\mid$ daz eq den ougen rate bôt (Wolfram von Eschenbach: Parzival. Studienausgabe. Mittelhochdeutscher Text nach der sechsten Ausgabe von Karl Lachmann [...]. Berlin - New York 1998, v. 145,17f.). Zur das Auge bedrohenden Farbintensität vgl. Elisabeth Schmid: weindiu ougn bânt süezen munt $(272,12)$. Literarische Konstruktion von Wahrnehmung im Parzival. In: Wahrnehmung im Parzival Wolframs von Eschenbach. Actas do Colóquio Internacional 15 e 16 de Novembro de 2002. Hg. von John Greenfield. Porto 2004, S. 229-242, hier S. 236: Rot als „Aggression des Auges“.

46 Die Verse 203 bis 300 fehlen in der kürzeren Fassung des cgm 714; dazu Keller (Anm. 40), S. 15; die Szene wird hier statt in der Kirche in der Küche angesiedelt.

47 Als „textexterne Anschlußkommunikation“ beschrieben von: Ludger Lieb und Peter Strohschneider: Die Grenzen der Minnekommunikation. Interpretationsskizzen über $\mathrm{Zu}-$ gangsregulierungen und Verschwiegenheitsgebote im Diskurs spätmittelalterlicher Minnereden. In: Das Öfentliche und Private in der Vormoderne. Hg. von Gert Melville und Pe- 
Die Geschichte zeigt, daß es gar nicht so einfach ist, zwischen toten und lebendigen, stereotypen und exklusiven Hyperbeln zu unterscheiden. Albern (der kind lop) oder ernst? Ironisch? Ironisch aus souveräner oder aus unsicherer Distanz? Ist die ,Ironie', die etwa darin liegen könnte, daß der Erzähler Formulierungen, an deren Repetition er zu leiden behauptet, selbst übernimmt, nur eine von uns wahrgenommene? Dann wäre sie vom Autor naiv übersehen? Was liegt vor, wenn einerseits die Abgedroschenheit von Formulierungskonventionen zum Thema wird, anderseits diese überboten werden sollen mit eben denselben Mitteln?

Um einen Standort über dem singulären Phänomen zu gewinnen, sei nachträglich Wolfram ins Spiel gebracht, in gebotener Kürze, mit drei Beispielfällen, die kürzlich Elisabeth Schmid im anderen Kontext des Problems der Wahrnehmung im ,Parzival ${ }^{k}$ zusammengestellt und analysiert hat: 48

(1) Als Parzival Jeschute zum zweiten Mal antrifft, ist sie zwar äußerlich heruntergekommen, doch ihrem Mund konnte die erlittene Unbill nichts anhaben:

swiez ie kom, ir munt was rôt:

der muose alsölhe varuve tragen,

man bete fiver wol drûz geslagen. (v. 257,18-20)

Der Vergleich ,feuerrot' wirkt auf den ersten Blick konventionell. Aber Wolfram läßt das hyperbolische Feuer nicht der Hitze des Mundes entspringen, sondern der Röte selbst. So steigert er die Farbe über alles vorstellbare Rot hinaus. Das ist durchaus ein Ansatzpunkt der oben vorgestellten Minnerede, die auf ihre Weise eine maximale Bild-Intensität sucht.

(2) Der eifersüchtige Orilus hatte angekündigt, er werde Jeschute Grund genug zum Weinen geben:

ich sol velwen iweren rôten munt,

[und] iwern ougen machen rate kunt. (v. 136,5f.)

Bleiche Lippen, rote Augen. Hier liegt eine metonymisch ausgelöste Überkreuzung rhetorischer Konventionen vor: Die Röte geht vom Mund auf die Augen über, die als gerötete ein Indiz sind für erlittenes Leid. Sichtbar wird auf engstem Raum die Verbindung von Minne und Gewalt.

ter von Moos. Köln - Weimar - Wien 1998 (Norm und Struktur 10), S. 275-305, hier S. 302 mit Anm. 50. Zum Schluß der Minnerede (Überlieferungsvarianz, Schreiberzusatz) vgl. Waltenberger (Anm. 39).

Schmid (Anm. 45), S. 232-234. 
Wolfram bringt typisch Farben an Stellen unter, wo sie für die geltenden Schönheitsstandards nicht hingehören. ${ }^{49}$

(3) die gâbe enpfienc der degen guot.

dô streich er von dem munde' $z$ pluot

und kuste sînes berzen trût. (v. 270,5-7)

Parzival besiegt Orilus im Zweikampf. Ein Kuß soll die Versöhnung von Orilus und Jeschute besiegeln. Aber Orilus, dem beim Kämpfen Blut aus der Nase gequollen war, hat einen blutverschmierten Mund. Sie küßt ihn trotzdem, und wieder wird - hier an dem buchstäblich blutroten Mund der Zusammenhang von Minne und Gewalt erkennbar.

Bereits mit diesen wenigen Wolfram-Stellen ergeben sich ganz verschiedene Konstellationen im Blick auf den feuerroten, fahlen, blutroten Mund und die naßroten Augen: metaphorisch gestörte Vergleiche stehen neben metonymisch gestörten Metaphern. Die Blutstropfenszene gehörte ebenso in diesen Zusammenhang (auch wenn die ,Rot-Weiß'-Semiotik hier wieder anders und komplexer ist). Immer wieder läßt Wolfram den roten Mund zum handelnden Subjekt von Überbietungsvergleichen werden (ir munt den bluomen nam ir prîs, Pz. 426,29)..$^{50}$ Nicht Parzival, sondern dessen personifizierter roter Mund sitzt stumm neben Cundwiramurs; der Mund, der zu Füßen gehört, die in Steigbügeln hängen, usf.: eine merkwürdige, wolframtypische Verschiebung von logischem und grammatischem Subjekt.

Verlassen wir damit das in der Lyrik (überwiegend der Neifen- und Morungen-Tradition) greifbare, in der Epik vor allem von Wolfram spezifisch umgesetzte ,Roter Mund'-Motiv und kehren zurück zur oben vorgestellten Minnerede, Der rote Mund'.

Unsere Beobachtungen lassen sich wie folgt zusammenfassen. Das organisierende Prinzip des Textes ist mit Händen zu greifen. Als eine Art Textgenerator fungiert die hyperbolische Metapher vom ,brennendroten Mund', die schon im Titel der Minnerede auf einen Superlativ zusteuert. ${ }^{51}$

49 Vgl. ebd., S. 233, außerdem Stephan Fuchs-Jolie: al naz von rate (Tit. 115,1). Visualisierung und Metapher in Wolframs Epik. In: Wahmehmung im Parzival Wolframs von Eschenbach. Actas do Colóquio Internacional 15 e 16 de Novembro de 2002. Hg. von John Greenfield. Porto 2004, S. 243-278. In der im Aufsatztitel zitierten Titurelstelle ist die Röte (und Nässe) rotgeweinter Augen vertauscht mit der erotisch attraktiven Röte des roten Mundes, über das Ineinandergreifen metonymischer und metaphorischer Bezüge.

50 Das Beispiel ist auch erwähnt bei Haferland (Anm. 30), S. 54.

51 Deren Attraktivität - allgemein gesprochen - könnte damit zusammenhängen, daß der Weg von der anschaubaren Idealität zur erotischen Attraktivität so kurz ist, außerdem verbale (sprich ,ja!) und nonverbale Kommunikation (Lächeln, Kuß, Gruß) ineinander über- 
Die hyperbolische Text-Generierung funktioniert nach einem einfachen Muster: dem Muster steigernder Häufung im ersten Teil, dem Muster einer konkretisierten Metapher im zweiten Teil (wo das metaphorische ,Brennen' des Mundes auf die Handlungsebene übergreift). Evident ist weiter, daß mit literarischen Anspielungen gearbeitet wird. Vor allem Wolfram wird herbeizitiert, an dessen sprachlichen Habitus der Erzähler anzuschließen versucht, um stereotypen Konstellationen und langweiligem Mittelmaß, wie er sagt, zu entkommen. Mit der uneingeschränkten Übertreibung der Sprechakte lop und klage steht darüber hinaus der Minnesang im Hintergrund. Außerdem wird schwankartig die Ordnung der Minne mit der religiösen Ordnung konfrontiert (durchweg: Heiligtum, Reliquien, groz wunder, Kirchenraum, Ostern, erotisiertes Psalmenzitat). Beide Textteile verbindet, daß das Prinzip der Übertreibung mit seinen Implikationen Übermaß und Überbietung auffällig dicht mitbesprochen wird (die Descriptio-Technik, der Rosen-Lilien-Topos, das ,von rot iehen, die Wolfram-Imitatio). ,Der rote Mund' ist also auch ein Metatext, ein Text über literarische Konventionalität im Horizont von Imitatio und Aemulatio. Er wechselt häufig und offen die Ebenen. Das wiederum stellt eine Distanz her, einen bescheidenen Spielraum für: Ironie.

Von diesen Überlegungen aus läßt sich zum Schluß zurückkommen auf die noch ausstehende Frage der Wertung. Unsicher ist nach wie vor, wie jene Techniken eingeschätzt werden sollen, mit denen die Minnerede ,Der rote Mund' das Mittel der Übertreibung nutzt, um in $\mathrm{ne} r \mathrm{~h}$ a $1 \mathrm{~b}$ der Konventionsbindung der Literatur a u $\mathrm{z}$ u f a $1 \mathrm{le} \mathrm{n}$. Immerhin konnten wir beobachten, daß der Text das Bewertungsproblem kennt und durchaus miterzählt, reimt er doch unter anderem die Exklusivität (aus gesundert) unvermittelt auf die Konventionalität (di $\beta$ ist ein red als bundert, v. 92f.), als wollte er markieren, daß Konventionsbrüche schneller, als es bemerkt werden kann, wieder zur Konvention werden. Daß der Erzähler den Trivialitätsverdacht für sich selbst ausblendet und ihn immer nur den andern zumutet, versteht sich von selbst. Programmmatisch unterscheidet er die Könner und die (hundertfachen) Stümper im Übertreiben und rückt als unübertroffenen Meister Wolfram sowie, in dessen Nachfolge, sich selbst weit nach vorn.

Die Ausarbeitung einer Theorie spezifisch mittelalterlicher Konventionsbindung der Literatur steht noch aus. ${ }^{52}$ Für die Poetik der klassischen Antike hat Friedrich Nietzsche folgenden Vorschlag gemacht:

gehen können. Die Vorstellung, daß man die Dame beim Sprechen küßt, also Kuß und Wort zusammenfallen, findet sich etwa bei Reinmar (MF 159,37) oder bei Walther $(43,37)$.

52 Vgl. dazu den Vorstoß von Franz Josef Worstbrock: Wiedererzählen und Übersetzen. In: Mittelalter und frühe Neuzeit. Übergänge, Umbrüche und Neuansätze. $\mathrm{Hg}$. von Walter Haug. Tübingen 1999 (Fortuna vitrea 16), S. 128-142. 
Die künstlerische Convention. - Dreiviertel Homer ist Convention; und ähnlich steht es bei allen griechischen Künstlern, die zu der modernen Originalitätwuth keinen Grund hatten. Es fehlte ihnen alle Angst vor der Convention; durch diese hiengen sie ja mit ihrem Publicum zusammen. Conventionen sind nämlich die für das Verständnis der Zuhörer eroberten Kunstmittel, die mühvoll erlernte gemeinsame Sprache $\left[\ldots . .{ }^{53}\right.$

Soweit Nietzsches Sicht auf „künstlerische Conventionen“, auf die Schemabindung und Vorlagenbindung der antiken Literatur, auf stereotype Konstellationen als Wissensspeicher und als ,mühvoll erlernte gemeinsame Sprache“. Eine ungelöste Stelle in einer Theorie spezifisch mittelalterlicher Konventionsbindung wäre der Stellenwert der Ironie, ein Problem, das ich auch für die auffällig übertreibenden Minnereden nur anstoßen konnte.

Ironie wäre dabei nicht im engeren Sinn einer rhetorischen (dissimulatio)-Figur geltend zu machen, die das Gegenteil des Gesagten anzielte, sondern, aus dem fest umrissenen Bereich der Rhetorik heraustretend, als eine Sprechhaltung, die die „Verstellung“ der Ironie auf die literarische Konfiguration übergehen ließe: auf das Verhältnis von Autor-TextLeser/Hörer. ${ }^{54}$ An mehreren Stellen ließ sich für den ,Roten Mund ein solches Heraustreten des Autors aus seinem Werk beobachten, eine augenzwinkernde Interaktion des Erzählers mit dem Publikum, die das eingangs von mir skizzierte Risiko der Übertreibung mitdiskutiert: Je unwahrscheinlicher Übertreibungen, um so dringlicher der Wahrheitsbeteuerungsbedarf. Übertreibungen lügen? $E_{z}$ ist wor (v. 78, 165, 167, 180, 321). Übertreibungen spielen? Ez ist kein spot (v. 320). Übertreibungen wirken künstlich? ,Macht ihr es besser!' (v. 349).

Im Blick auf die Gattung Minnerede schiene es mir auch lohnend, nach ironischen Reimen zu fahnden. Lohnend wäre darüber hinaus die Suche nach Texten, die die Gattung Minnerede als solche ironisch distanzieren, deutlicher noch als ,Der rote Mund' dies - vielleicht - tut. Ein Beispiel dafür, zum Schluß:

Unter dem Namen ,der König vom Odenwald ${ }^{45}$ sind im Anschluß an Lieder Reinmars in der, Würzburger Liederhandschrift' eine Reihe von Texten aufgezeichnet, reden, die das Genus der klassisch-höfischen lopRede parodieren und ihre komische Wirkung aus dem Gefälle von literari-

53 Friedrich Nietzsche: Menschliches, Allzumenschliches II. Der Wanderer und sein Schatten, Nr. 122, KSA 2, S. 604.

54 Dazu im Überblick Ernst Behler: Ironie und literarische Moderne. Paderborn u. a. 1997, bes. S. 21-69.

55 König vom Odenwald: Gedichte. Mittelhochdeutsch-Neuhochdeutsch. Mit einer Einleitung zur Klärung der Verfasserfrage, hg. und übertragen von Reinhard Olt. Heidelberg 1988, Nr. VII. Vgl. dazu Gisela Kornrumpf: Der König vom Odenwald. In: ${ }^{2}$ VL 5 (1985), Sp. 78-82. 
scher Ambition und Gegenstandsniveau beziehen. Sie gehören in die erste Hälfte des 14. Jahrhunderts. Eine dieser reden kündigt gleich im ersten Vers spehe funde an, beginnt dann aber mit einem unverborgen stereotypen Eröffnungsthema, nämlich mit einem Traum, wie sich das für eine Minnerede gehört. Dieser Traum häuft das gesamte topische Arsenal (Begegnung mit schöner Dame, Dialog, Belehrung): Unter einem Baum begegnet dem Ich eine schöne Dame. Eine höfische Kommunikation setzt ein, ausdrücklich voller zubt, umständlich (Sag mir, König, wonach steht dein Verlagen?‘ - ,Ich will mich bei Dir niedersetzen). Man kommt sich näher, Rede und Gegenrede gehen vorhersehbar hin und her. Dann kündigt die frawne wolgetan im Flüsterton eine Frage an, doch unsere naheliegende Erwartung auf eine Minnefrage wird enttäuscht. ,Unterweise mich', wispert sie nämlich, ,warum die Männer jetzt immer so lange Bärte tragen‘:

\section{„Du solt mich unternise, \\ Die die langen berte tragen. \\ $V$ on den solt du mir etwaz sagen. \\ Wie sie daz nu gemeinen. " (v. 20-23)}

Das Ich läßt sich nicht lang bitten, erläutert, systematisch numerierend von 1-10, verschiedene Semantiken des Barttragens, kulturhistorisch aufschlußreich, aber poetologisch deplaziert. Bärte, erfährt die Dame, bezeichnen fallweise einen Rachewunsch, Sühnebereitschaft, die Teilnahme an einer Wallfahrt, Männlichkeit, Eitelkeit oder die Lebensform des Mönchs. Die Dame dankt, dreht sich um. Während sie schon weggeht, läßt sie noch eine Bemerkung fallen: ,Gib acht - und wir sollten wohl davon ausgehn, daß der Gefragte selber einen Bart trägt -, mir gefiele es, wenn einem der Bart $\mathrm{nicht}$ in den $\mathrm{W}$ e in $\mathrm{h}$ in ge beim Trinkenc. Was ist hier passiert? Durch die unerwartete Konfrontation des Traumeingangs mit dem literaturungewohnten Stoff, auch durch die zum Schluß hergestellte Verwirrung von zeichenhaftem und buchstäblichem Aussagestatus (Semiotik der Bärte/, hängt sie doch nicht immer in den Wein!) entsteht eine zugegeben mäßig witzige Pointe.

Das in den reden des Spätmittelalters sonst allgegenwärtige Minnethema ist auffällig ausgespart, und nicht nur in dieser, sondern auch den anderen reden desselben Autors, die Titel tragen wie: ,Vom Lob der Kuh', ,Lob der Gänse', ,Vom Stroh` oder ,Die Badefreuden‘. Soll das heißen: Die Minne ist ein zu ,triviales` Thema? Oder braucht der Autor es umgekehrt gerade als abwesendes, zur Konstruktion seiner Pointe? Feststellbar ist jedenfalls auf der einen Seite die Sensibilität für eine gewisse Übersättigung, anderseits und zugleich das Bedürfnis, weiterzumachen. Durch den Kontrast der erzählten Situationen (Die Dame, die sich belehren lassen will, gibt selber eine schnippische Lehre zurück) entsteht ein ironischer Stilbruch, wie ihn auf andere Art auch bereits die Diskrepanz zwischen 
Inhalt (Bärte) und Form (Traumeingang) hervorgekehrt hatte. Gleich zu Beginn wurde der Minneredeneingang als Topos überspielt und mit theatralischer (übertreibender) Geste ad absurdum geführt.

\section{Schluß}

Damit bin ich am Ende meiner Überlegungen angekommen. Aus meinen Beobachtungen, die an der ,hyperbolischen Hyperbolik' der Minnerede ,Der rote Mund' ansetzten, möchte ich abschließend folgende Schlußfolgerungen ziehen.

(1) Übertreibungen betreffen stets das Verhältnis zu einer Grenze. Übertreibung gilt als Abweichung vom Maß. Nur konsequent wird, quer durch die Gattungen, das Minnethema von Anfang an als Relation von minne und mâze verhandelt; ist es immer zugleich Stil-, Moral- und Affektdebatte. Im Spätmittelalter schließlich wird das Minnethema, längst Toposwissen und verfügbarer Bestand ${ }^{56}$, geradezu universal, Katalysator und Wertzentrum ganz heterogener Debatten.

(2) Im spätmittelalterlichen Liebesdiskurs schließt die Überbietung besonders dringlich die Überbietung der literarischen Tradition ein. Wer spricht, muß sich vor dem Hintergrund des schon Gesagten mehr denn je Gehör verschaffen, ist er doch einer immer größeren Rivalität von Aufmerksamkeiten ausgesetzt. Der Effekt ist eine uneingeschränkte und gewissermaBen unendliche Übertreibung der Übertreibung, wie sie der ,Rote Mund“, ganz und gar vom ,Unwahrscheinlichen' überwuchert, exemplarisch vorführt.

(3) Der Übertreibung eignet eine Gleichzeitigkeit von Konvention (red als bundert) und Konventionsbruch (aus gesundert). Daraus resultiert ein paradoxer Effekt: Ein großer Teil der Minnereden (um so mehr die sogenannten ,geblümten) forcieren die Abweichung, den Konventionsbruch, und produzieren zugleich die Einzigartigkeit in Serie.

(4) Von der Lyrik erben die seriell produzierten Minnereden das Doppelthema Liebe und Sprache. ,Ich liebe' und ,Wie spricht man über Liebe?" sind asymmetrische Perspektiven, so daß - auch noch in den Minnereden

56 Ein Überblick bei Rüdiger Schnell: Causa Amoris. Liebeskonzeption und Liebesdarstellung in der mittelalterlichen Literatur. Bern - München 1985 (Bibliotheca Germanica 25). Besonders auffallig verteilen in der ,Minneburg' die drei Prologstrophen das Wirken der Minne absteigend auf Gott, den Kosmos und das Ich. 
- unumgänglich Objekt- und Metaebene, Ich-perspektivisches und exemplarisches Sprechen ineinanderfließen. Auch das könnte ein geschätzter Reiz sein. Die Auseinandersetzung mit dem Paradigma der Minnelyrik einerseits, die Konfrontation mit einer neuen Einstellung (meisterschaft, Wissen) anderseits bewirkt, daß sich in den zunehmend wissensgesättigten, häufig allegorisch dominierten Minnereden ästhetische und theoretische Einstellung immer mehr berühren. Die Diskussion der Kontextbeziehungen würde auf die von der Forschung nicht ausgeleuchtete Frage führen, wie genau sich die Verlagerung des Minnediskurses vom Minnelied auf die Minnerede in überlieferungsgeschichtlicher, poetologischer und konzeptioneller Hinsicht auswirkt.

(5) Die Beliebtheit der Minnereden könnte zusammenhängen mit der an Hyperbolik gebundenen hohen Flexibilität der Anteile Imagination, Reflexion, Narration. Was übertreibend vorgestellt, reflektiert, erzählt werden soll und warum gerade dies vorgestellt, reflektiert, erzählt werden soll, das bliebe von Fall zu Fall zu gewichten und zu bestimmen. ${ }^{57}$ Wo aber, allgemein gesprochen, Imagination, Reflexion und Narration so flexibel zusammenspielen, liegt ein Ineinandergreifen der Aussageebenen nahe. Wörtlichkeit und übertragene Rede können wechseln (so, für unser Beispiel gesprochen, der buchstäblich und übertragen brennende rote Mund). Ebensogut können allegorische und narrative Ebene wechseln, kann Wahrscheinliches und Unwahrscheinliches mit wechselnden Anteilen gegeneinander verrutschen: qua Übertragung und qua Übertreibung. (Der in dieser Hinsicht einschlägige, zum Schluß von mir zitierte Text über die Semantik des Barttragens hätte im Karlsruher Codex 408 eine Entsprechung in einer kleinen rede mit dem Titel Die sechs varb. ${ }^{58}$ )

(6) Ist die ,Kunst der Übertreibung' in den spätmittelalterlichen Minnereden nun ,trivial? Die heikle Frage der Wertung wollte ich zugunsten einer ,rein' funktionalen Perspektive nicht ausklammern. Mein Vorschlag war eine Binnen-Differenzierung: Wer übertreibt, kann etwas zum Vorschein bringen, was sonst unbemerkt bliebe oder was unbemerkt geblieben ist. Das wäre die Erkenntnischance der Übertreibung und zugleich ihr möglicher ästhetischer Gewinn: eine sprachlich-imaginative Vervielfälti-

57 Vgl. Bertau (Anm. 20), S. 286.

58 Text in: Schmid (Anm. 40), S. 79-84. Hier läßt sich umgekehrt die Dame zeichenhaft Verschlüsseltes vom Ich erklären. Skeptisch fragt sie nach, warum und inwiefern die Frauen auf einmal mit der Farbe ihrer Kleidung ihren Herzenszustand verraten. Zwar ist sie einerseits mißtrauisch solcher Farbmarkierung gegenüber und klagt Verschwiegenheit ein, um die Gefahr der Manipulation und Übertreibung (!) zu bannen (v. 55ff. und 128). Anderseits läßt sie sich die Farbsemantik (Grün für den Liebesanfang, rot für das Feuer der Liebesqual, Blau für die Beständigkeit etc.) doch recht gern erklären. 
gung von Aspekten und Möglichkeiten durch Häufung, Zuspitzung, Übertragung, Ironie. Übertreibung kann aber ebensogut etwas zum Verschwinden bringen. Dann bliebe sie (diskursiv, ästhetisch) leer. Mit dieser Ambivalenz hyperbolischer Rede hatte ich begonnen. Nur eine Übertreibung, bei der die Steigerung von Reizen mit der Verfeinerung von Aufmerksamkeit einherginge, nur eine Übertreibung, die sich nicht erschöpfte in der Relation zum Gegebenen, wäre - vorläufig gespochen - ,nichttrivial".

Eine Antwort auf die Frage nach der Funktion der Minnereden könnte demgegenüber so aussehen: Übertreibung reagiert auf Übermächtiges, Undurchsichtiges. Für das Minnethema sind über die Jahrhunderte zwei Dauerirritationen stehengeblieben: ,Ist die Liebe wahr?" und ,Ist sie dauernd?" Nichts anderes beschwören die unendlichen Übertreibungen der Minnereden: die Unbeweisbarkeit (Unbegründbarkeit) und unmögliche Ständigkeit der Liebe. Neu? daz alte spil, das älteste. 